\title{
EL CUERPO FEMENINO Y EL CONCEPTO DE BELLEZA EN DOS CUENTOS DE CARMEN NARANJO
}

\author{
Carmen Tisnado
}

\begin{abstract}
RESUMEN
Este estudio consiste en una lectura detallada de los cuentos "Ondina" y "Simbiosis del encuentro", de Carmen Naranjo. Siguiendo ciertos postulados de Michel Foucault y de algunas teorías feministas, el análisis de ambos cuentos sugiere que Naranjo propone una manera de resistir y confrontar los patrones socialmente establecidos con respecto al cuerpo femenino. Naranjo desmitifica el concepto de belleza femenina, y a partir de esta desmitificación, invita a que ya no sea más el cuerpo lo que defina a la mujer.

Palabras clave: cuerpo, belleza, mito, construcción, género.
\end{abstract}

\begin{abstract}
This study consists of a close reading of "Ondina" and "Simbiosis del encuentro," short stories by Carmen Naranjo. Following what Michel Foucault and some feminist theories suggest, the study suggests that Naranjo, in her two stories, offers a way to resist and confront socially established patterns regarding the female body. Naranjo turns around the myth of women's beauty and in doing so, presents the idea that the body should no longer be what defines woman.
\end{abstract}

Key words: body, beauty, myth, construction, gender.

Carmen Tisnado. Department of Spanish, Franklin \& Marshall College. Lancaster, PA.

Correo electrónico: carmen.tisnado@fandm.edu 
Al comentar Más allá del Parismina (2000), de la escritora costarricense Carmen Naranjo, Virginia Borloz Soto señala que "la autora utiliza el lenguaje crudo, la palabra directa calificada de grosera y fea, la no oficial y la no legitimada, propia del carnaval . .." (3). Lo mismo se podría indicar con respecto a muchas de las obras de Naranjo. La autora, con cierta irreverencia y bajo una aparente incorrección política, se sirve de la noción de lo carnavalesco y de lo grotesco en sus representaciones narrativas.

En los dos cuentos que analizo en este trabajo - "Ondina" y "Simbiosis del encuentro"- por ejemplo, Naranjo trata el cuerpo humano desfigurado. Paradójicamente, no es en esta desfiguración física donde se plasma lo grotesco sino en la manera en que la autora hace que sus personajes la vivan y reaccionen ante ella. El cuerpo, en estos cuentos, asume la calidad de grotesco, lo que lleva a que los lectores lo puedan considerar ajeno, distante. Naranjo parece sugerir que esta distancia, especialmente con respecto al cuerpo femenino, es un paso necesario para su desmitificación, pues el mito que más destaca en la sociedad occidental con respecto al cuerpo de la mujer es el de la belleza.

Por un lado, "Ondina" fuerza a que los lectores reconsideren el concepto de belleza femenina, y la manera en que éste enmarca la relación entre los géneros. Por otro lado, "Simbiosis del encuentro", en su tratamiento del cuerpo, invita a los lectores a que acepten la noción de género como producto de una práctica discursiva asentada en un uso ininterrumpido y no cuestionado, como lo sugieren las teorías feministas desde hace ya algún tiempo.

Naranjo, en una entrevista con Chalene Helmuth, declara que cuando "está hablando una mujer, está apropiándose de la palabra, algo que siempre se le había negado" (48). Cuando Helmuth le pide que nombre una palabra clave que se refiera a la mujer, Naranjo no duda en enunciar cuerpo,"porque cuerpo es algo que la define a una frente a todos, pero que no la define a una misma" (49). Es precisamente alrededor de la idea de cuerpo, en combinación con los conceptos de lo bello y de lo grotesco, que la autora construye las narraciones de "Ondina" y de "Simbiosis".

Los dos cuentos aparecen en la colección que lleva el título de Ondina, publicada en 1983. Ambos presentan situaciones que, por motivos diferentes, son inusitadas. En "Ondina", el personaje masculino se siente fascinado por una enana cuyas costumbres sexuales él mismo califica de grotescas. En "Simbiosis", el personaje masculino pasa por la experiencia de embarazo y parto. Si tenemos en cuenta las expectativas culturales que todavía imperan con respecto a la estética del cuerpo de la mujer, la primera situación representa algo que va en contra de la norma. Por su parte, la segunda representa algo que es biológicamente imposible.

La narración de ambas historias está en primera persona. En "Ondina”, Vega cuenta cómo "se enamora" de Ondina, y lo que hace para poder vivir cerca de ella. En "Simbiosis", Ana cuenta de su relación con Manuel, desde el momento en que se conocen hasta el momento en que se separan. "Ondina" empieza in medias res, cuando Vega relata la invitación que recibe para "tomar un café informal" en casa de los Brenes, padres de Mercedes, su ex-secretaria. El primer párrafo del cuento, en una sola frase, caracteriza al personaje: "Cuando me invitaron para aquel lunes a las cinco de la tarde, a tomar un café informal, que no sabía lo que era, si café negro con pastel de limón o con pan casero o café con sorbos de coñac espeso, todo lo pensé, todo, menos la sorpresa de alguien que se me fue presentando en retazos: Ondina" (9). Vega, es casi evidente, acude a la invitación sin ningún interés especial y sin mucha expectativa. Las palabras que enuncia hacen pensar que, efectivamente, él conoce a Ondina esa tarde. Luego, sin embargo, revela que únicamente 
vio su retrato. Más aún, sale de casa de los Brenes sólo con el conocimiento del nombre de Ondina, sin saber que ella es la hermana menor de Mercedes, con quien Vega mantiene una relación cordial, pero lejana.

Desde el momento en que Vega descubre el retrato de Ondina en un cuadro de la pared de la sala, queda hechizado por lo que él mismo describe como "una joven bellísima, de ojos claros y fuertes" (12). De manera obsesiva, Vega empieza a imaginar a Ondina durante la vigilia y sueña con ella mientras duerme. A pesar de que sabe que vio solamente un cuadro, actúa como si hubiera conocido a Ondina en persona. Le atribuye a Ondina la capacidad de acción que, en este contexto, no tiene: "sus ojos, los ojos de Ondina, me seguían, me respondían, me acariciaban" (12). Es, curiosamente, en las instancias en que describe a Ondina cuando, por primera vez, Vega expresa certeza, aunque infundada: "La supe atrevida, audaz, abiertamente alborotada" (12; el énfasis es mío). La imagina, además, alta y esbelta. Tanto los sueños de Vega como los actos de su imaginación tienen un tono marcadamente sexual y es siempre Ondina quien asume un papel activo: "[Ondina] abría la puerta y saltaba a mi cama. Ella siempre me desnudó y después jugó con mi sexo hasta enloquecerme” (13).

Hasta este momento podrían interpretarse las acciones de Vega como producto de su soledad y de su probable celibato. Dominado por la inercia, se desenvuelve mejor dentro del mundo ficticio que se está construyendo. Pero esto cambia pronto. Sobre la base de su imaginación, se declara enamorado y decide ir a casa de los Brenes para comunicarle al padre de Ondina su deseo de casarse con ella. El Sr. Brenes lo desanima enfáticamente: "Me oyó sonriente y me contestó que lo olvidara, era imposible, Ondina no me aceptaría, había rechazado a muchos mejores que yo" (14).

El comentario del Sr. Brenes, en parte, confirma la imagen de belleza que Vega da de Ondina: con sus múltiples pretendientes, Ondina encaja en el estereotipo cultural según el cual muchos hombres aspiran a estar con una mujer bella. Vega le ve sólo el rostro, y a partir de la belleza que ve en él, imagina un cuerpo alto y esbelto. Asimismo, el nombre de Ondina solicita la evocación, aunque inconsciente, de belleza. Ondina, como ninfa bella de diversas mitologías occidentales, pertenece al imaginario colectivo de la representación de lo bello.

Después de intentos fallidos de volver a casa de Ondina, la inesperada muerte de los señores Brenes le da a Vega una excusa para presentarse en el velorio como el novio oficial de Mercedes, con el solo objetivo de ver a Ondina. Ya en casa de los Brenes, presencia una escena en la que "una enana ... se dejaba lamer el sexo muy grotescamente por un gato" (16; el énfasis es mío). Vega siente horror y atracción al mismo tiempo, pero no se ocupa de pensar en lo que ve, y más bien se refugia en la sala, dedicándose a contemplar el cuadro de Ondina y a imaginar escenas eróticas con ella. Vega le da importancia a la enana que vio sólo cuando, poco después, se da cuenta de que ella es Ondina:

Cuando desperté, noche ya, estaba organizado el rosario. . . A Apareció entonces Merceditas pálida y desfallecida, vestida de negro absoluto, con sus pechos erectos, abundantes, bien sostenidos, y de la mano, también en negro absoluto . . . la enanita más diminuta y bella que había visto en mi vida, con los ojos de Ondina, con el pelo rebelde de Ondina, con los labios carnosos y trémulos de Ondina (16-7).

Vega ya no imagina más. Ve el cuerpo enano de Ondina y parece no importarle que la imaginó alta y esbelta, atributos que, para él, resaltaban su belleza. Vega piensa en ella como "suave, dulce, una niña apenas" (17). Poco después, Ondina se le acerca, y agresivamente, aunque sin hablarle, inicia un contacto sexual con él, no consumado porque lo interrumpe el gato. 
A partir de este momento, Vega busca obsesivamente una solución que le permita encontrar "la clave de la convivencia" (17). Al mes se casa con Mercedes. "A la boda asistió Ondina. El gato se quedó en la casa" (17).

Es importante caracterizar el lenguaje con que Vega se refiere a Ondina. Cuando no la reconoce, Vega habla de "una enana", y cuando finalmente la ve y distingue los rasgos que vio en el cuadro, se refiere a "la enanita". El diferente uso de los artículos revela la cercanía con que Vega piensa en Ondina. Cuando no sabe de quién se trata, el artículo indeterminado sugiere que la única característica especial que ve en Ondina es su conducta grotesca con el gato. Vega no resalta la belleza de su rostro; es más, parece no observarla. Cuando reconoce a Ondina, sin embargo, usa el artículo determinado, sugiriendo un tratamiento único, especial. Es de mucha mayor significancia, sin embargo, el uso del diminutivo cuando Vega reconoce a Ondina. "La enanita" implica cariño, apego. Aunque ambas referencias sean con respecto a la misma persona, Vega decide olvidar el episodio entre Ondina ("una enana”) y el gato, y seguir concentrándose en sus actos imaginarios con Ondina ("la enanita").

En el velorio, Ondina aparece de la mano de Mercedes, lo cual da un anticipo de lo que será el triángulo en que ambas van a vivir con Vega. La convivencia a la que alude Vega, sin embargo, no se refiere exclusivamente a que al casarse con Mercedes podrá vivir también con Ondina. El gato ocupa un papel de importancia, y al hacerlo, plantea la existencia de un segundo triángulo, quizá más difícil de eludir, pues el gato representa una fuerza salvaje que, al final, domina la situación. En la vida pública, Mercedes y Ondina cumplirán sus papeles de esposa y cuñada, respectivamente, pero, en la vida privada el gato permanece en la casa. La alusión a los futuros encuentros entre Ondina y el gato es evidente, y esto parece alimentar las fantasías y deseos de Vega. La subordinación de Vega con respecto a Ondina llega aquí a un nivel mucho mayor. No es que únicamente él se somete a la voluntad de ella, sino que al someterse, ingresa al mundo grotesco y bestial por el que él mismo, en un comienzo, siente repulsión.

"Ondina" rompe esquemas impuestos por la normatividad patriarcal. Esta ruptura se plasma a nivel lingüístico y a nivel temático. Naranjo hace que la voz narrativa sea masculina. Si sólo prestáramos atención a este punto, concluiríamos que el cuento ratifica los estereotipos que le otorgan al hombre el poder de la palabra. Sin embargo, la ironía aquí radica en que mientras Vega habla desde su perspectiva de agente que controla los acontecimientos, existen muchos indicios que más bien lo sitúan como objeto de la voluntad de Ondina, sin control de nada.

A nivel temático, Naranjo crea una situación que se aleja de todo estereotipo. Cuando Vega sólo imagina a Ondina, desconoce que es enana, y cuando finalmente la ve, contra las expectativas en cuanto a la conducta masculina que genera el estereotipo de belleza femenina, no le da importancia al cuerpo enano de Ondina ni a sus acciones, y termina aún más obsesionado con ella. Esta reacción, en una primera lectura, podría registrarse como una contradicción de Naranjo con respecto a su noción de cuerpo femenino, pues el cuerpo de Ondina no la define ante Vega.

En "Ondina", Carmen Naranjo propone cierta confrontación de la noción de belleza femenina que domina en la sociedad occidental. Las ideas propuestas por Michel Foucault con respecto al cuerpo, así como los postulados de diversas teorías feministas, concuerdan en que la noción de la mujer bella se configura dentro de una oposición binaria que se traduce en una imposición cultural, socialmente construida. Para que se la considere femenina, 
la mujer ha tenido (¿tiene?) que someterse a la idea dominante de lo bello, y ha tenido que -o peor aún, ha querido- (o tiene que, o quiere) amoldarse a las características imperantes en cuanto a la belleza femenina. Las obsesiones culturales por el ideal de belleza femenina se convierten en obsesiones individuales de mujeres que quieren alcanzar, a toda costa, el perfil de lo culturalmente impuesto como bello. Los múltiples casos de anorexia nerviosa, las constantes visitas a cirujanos plásticos, las millonarias compras de cosméticos, entre otras cosas, son prueba del rigor inexorable al que, hasta cierto punto en forma voluntaria, se someten muchas mujeres.

Foucault asocia la disciplina corporal con el modo de operar de ciertas instituciones, por ejemplo, la escuela o la prisión. A partir de la teoría de Foucault, Sandra Lee Bartky explica el dolor emocional y físico al que se somete la mujer para que su cuerpo sea bello: “ ... insofar as the disciplinary practices of femininity produce a 'subjected and practiced,' an inferiorized, body, they must be understood as aspects of a far larger discipline, an oppressive and inegalitarian system of sexual subordination" (143). En este sentido, el personaje de Ondina rompe con el mito de la belleza femenina. Ella no considera su cuerpo enano como un cuerpo inferiorizado, y Vega tampoco lo hace. En gran parte esto representa, en "Ondina”, la ruptura de la subordinación sexual de la mujer. A diferencia de lo que explica Bartky, Ondina no se subordina sexualmente ante nadie. Es Vega, más bien, el subordinado. De este modo, Ondina asume el papel de femme fatale: en general, muchos hombres quieren, sin lograrlo, estar con ella y, en particular, Vega se obsesiona con acercársele.

Hay diversas maneras de comprender el concepto de femme fatale. Lisa Morton, en su estudio de dos películas, una australiana y otra neozelandesa, lo define de la siguiente manera:

\footnotetext{
The femme fatale is another example of woman defined in relation to her sexuality. She is a figure of excess; of a dangerous and threatening sexuality. She is also the antithesis of the maternal for she produces nothing. There is a sense of mystery about her, a 'secret' to be explored, which is the very fact of her excessive sexuality. For these reasons she is a figure of discursive unease, she threatens instability as her power is in revealing fears of uncontrollable drives which could lead to the loss of agency and subjectivity (5).
}

Ondina, de hecho, hace que Vega, al no poder controlar su pasión por ella, pierda agencia y subjetividad. Además, la sexualidad de Ondina se presenta como excesiva y, tanto antes como después de que se la "vea," mantiene cierto halo de misterio. En estos sentidos, Ondina se sujeta a lo descrito por Morton.

Aunque Morton no lo señale, es evidente que la femme fatale, en su aspecto físico, sigue el patrón socialmente impuesto de belleza femenina. La ironía de "Ondina" radica en que la femme fatale es enana. Aún en el siglo veintiuno y a pesar de la corrección política de muchos, algunos todavía asociarán la figura del enano a la de personajes circenses. Desde aquella perspectiva, el cuerpo enano se podría categorizar dentro de lo que Mikhail Bakhtin califica, en su estudio de lo carnavalesco, como "el cuerpo grotesco". Mary Russo define el cuerpo grotesco de la manera siguiente: "[it is] the open, protruding, extended, secreting body, the body of becoming, process, and change. The grotesque body is opposed to the classical body, which is monumental, static, closed, and sleek ..." (325). De modo paradójico, el nombre de Ondina, como indiqué antes, evoca la belleza clásica.

La Ondina de Carmen Naranjo, a diferencia de la Ondina mítica, carece de belleza clásica. Más aún, su cuerpo está en oposición de lo que se afirma del cuerpo bello clásico. Por otro 
lado, el cuerpo de Ondina se mantiene abierto a la experimentación sexual. A manera de corroboración de su calidad de "grotesco", es cuando está con el gato que el cuerpo de Ondina permanece más "abierto". Ondina se abandona ante el placer que el gato le hace sentir. Con Vega, su encuentro sexual es diferente. Ella es quien mantiene todo el control; él es quien se abandona.

Si dentro del estereotipo de belleza clásica, el cuerpo enano se percibe en algunas instancias como grotesco, puede ser percibido también como monstruoso. Rosi Braidotti, en su análisis sobre monstruos y madres, señala que la monstruosidad y la normalidad se entienden socialmente como una oposición binaria: "the monster is the bodily incarnation of difference from the basic human norm; it is deviant, an a-nomaly; it is abnormal. . . the very notion of the human body rests upon an image that is intrinsically prescriptive: a normally formed human being is the zero-degree of monstrosity" (62). Agrega Braidotti que, según la clasificación de monstruosidad hecha en el siglo diecinueve por Geoffrey Saint-Hilaire, "bodily malformations have been defined in terms of 'excess,' 'lack,' or 'displacement of organs"'(62). El cuerpo de Ondina carece del tamaño que le conferiría "normalidad”, y al mismo tiempo posee una sexualidad excesiva que también le impide pertenecer a la norma patriarcal de lo femenino.

Ondina encarna, pues, tanto a la femme fatale como a la mujer-monstruo o mujer grotesca. A pesar de que no está socialmente establecida como oposición, podríamos considerar que la mujer-monstruo y la femme fatale constituyen una. En "Ondina", Naranjo rompe esta oposición. En su protagonista confluyen la fascinación y el horror, tal como dice Braidotti que confluyen en la figura de lo monstruoso: "[monsters] also represent the in between, the mixed, the ambivalent as implied in the ancient Greek root of the word 'monsters,' teras, which means both horrible and wonderful, object of aberration and adoration" (62). Ondina es también objeto de adoración y aberración. A Vega le repele ver que ella siente placer cuando el gato le lame la vagina, pero al mismo tiempo, presenciar este acto significa, para él, una intensificación de su interés sexual en Ondina, lo que contribuye a que sienta aún más atracción por ella.

Carmen Naranjo, en "Ondina”, parece sugerir que, en efecto, la noción de belleza es una construcción social, y, además, ofrece la posibilidad de desconstruir, y por lo tanto destruir, esa construcción. Naranjo parece responder a las preguntas que se plantea Braidotti cuando explica, con respecto a la norma de belleza, que la idea de "diferencia" crea un concepto de "otro", y por lo tanto configura y sostiene una oposición binaria: "Can we free difference from these normative connotations? Can we learn to think differently about difference?" (62). "Ondina" le responde con un marcado intento de, efectivamente, considerar "la diferencia" de un modo nuevo, diferente.

A través de la mirada de Vega, "Ondina" propone la reformulación del concepto de otredad y de diferencia. Pero esa reformulación no carece de ambigüedades y aún de aparentes contradicciones. Por un lado, a Vega no le importa el aspecto del cuerpo de Ondina. Por otro, el amor que dice sentir por ella tiene un carácter dudoso, pues, de hecho, él no la conoce. Es importante insistir en que cuando la ve en persona, Ondina más bien le repele. Pero en este punto, Vega parece estar ya bajo el control de la fascinación que siente por el retrato de ella. Luego, Vega deja de lado "la diferencia" del cuerpo de Ondina e insiste en su enamoramiento, pero, irónicamente, el acto de enamorarse obedece al solo hecho de haber visto, en un retrato, el rostro aparentemente bello de Ondina. ¿Cuán "diferente" es, entonces, la actitud de Vega? ¿Acaso no es una conducta típicamente masculina dentro de la sociedad hegemónica patriarcal que exige un rostro bello en la mujer? 
Si bien en "Ondina” el cuerpo clásico femenino no es más que el objeto que el hombre aspira poseer, tampoco se ve la apreciación masculina de las cualidades personales del personaje femenino. No hay, pues, un cambio rescatable o prometedor en la conducta masculina, a pesar de que Vega no siga la norma patriarcal imperante. Es, más bien, como si Vega creara un nuevo estereotipo en el que, de nuevo, se tipifica, no sin desmedro, el perfil femenino.

Además de la disyuntiva sugerida, "Ondina" presenta una inversión de los papeles tradicionales. Vega, aunque cree ser quien toma las decisiones, termina adoptando las características femenistas de subordinación. Es Ondina, de manera silenciosa, quien asume las características masculinas de dominio. Ondina, intencionalmente, alimenta el deseo sexual de Vega, y él, en su decisión de casarse con Mercedes, cree encontrar "la clave de la convivencia" con Ondina, pero es incapaz de darse cuenta de la trampa que él mismo se tiende, pues vivir con Ondina le significa tener que vivir con Mercedes y, sobre todo, aceptar que el gato ocupará un lugar de prioridad en las elecciones sexuales de Ondina. Al final, es Vega el que lo acepta todo y quien se ve forzado a modificar su conducta. Aunque no es una inversión directa en cuanto a la conducta estereotípica de los géneros, en "Ondina" se presenta una inversión en cuanto al estereotipo de las expectativas tanto del personaje masculino como del personaje femenino con respecto al otro.

En cambio, Ana y Manuel, los protagonistas de "Simbiosis del encuentro", experimentan una inversión directa en sus papeles, es decir, tanto en sus respectivas conductas como en sus expectativas. Además, buscan, como Vega, pero sin poder encontrarla, "la clave de la convivencia”. Esta historia está narrada por Ana, quien inicia su relato contando su primer encuentro con Manuel. Las palabras de Ana, en un principio, pertenecen al estereotipo del código lingüístico femenino. Habiendo aceptado tener una "cita a ciegas" con Manuel, cuando está a escasos minutos de conocerlo en una fiesta, Ana prefiere irse antes de hablar con él, pero él la persigue y la detiene en la calle: "Se me escapaba, pero vine por usted y no quiero perderla. ¿Nos podemos tomar un café?” (36). A pesar de que las palabras de Manuel formulan una pregunta, Ana responde como si ésta fuera una exigencia, y se somete a ella: "Su voz fue imperativa y convincente. No dejó alternativa" (36). Ana se presenta como un personaje indeciso y de voluntad frágil que se coloca como objeto de la voluntad de Manuel. Desde el momento en que toman el café juntos, Ana y Manuel se constituyen en pareja. Del restaurante van al apartamento de Ana, donde viven una semana de exclusiva pasión.

Poco a poco se desvanece la pasión y los encuentros entre Ana y Manuel se convierten en una rutina que más bien les causa tedio. De la monotonía aburrida y silenciosa pasan a las discusiones verbales que los alejan cada vez más hasta que optan por separarse una semana, con la idea de que "después todo iba a ser diferente, porque la ausencia y echarnos de menos dan verdaderas dimensiones a la relación humana" (38). A partir de la separación, los cambios en el discurso de Ana y de Manuel son muy significativos. Ana, serena, totalmente conforme con no verlo, tiene que apaciguar a Manuel, quien habla como el personaje débil que no puede aceptar estar sin la compañía de Ana.

La transformación discursiva de Ana, de manera especial, refleja la transformación que ocurre en ella como personaje. Sin los tonos de pasividad y falta de iniciativa de antes, Ana asume un papel activo que le permite buscarse alternativas e impulsarlas a que se realicen. No es el discurso de Ana, sin embargo, lo único que se transforma. Surge una situación inverosímil que le da al cuento el carácter de parodia: Manuel está "embarazado". Sufre de vómitos y le crecen los senos. Ana, ante esta situación, asume un modo de hablar que se enmarca dentro 
del estereotipo del discurso masculino: "Lo aguanté más allá de la repugnancia que me daba su aspecto y empecé a vomitar yo también" (39). Es Ana, en un papel hegemónicamente machista, quien rechaza la condición de maternidad de Manuel, y al hacerlo, lo rechaza a él.

Manuel y Ana, avergonzados del estado en que él se encuentra, huyen a otra ciudad para que Manuel dé a luz. Al día siguiente de haberlo dejado en un hospital, se sorprende no sólo de no encontrarlo sino de escuchar que nadie lo recuerda. Ana empieza una intensa e infructífera búsqueda. Por último, en la soledad de su apartamento se presenta como producto, ella también, de una transformación de sexo. Se le enronquece la voz y le crecen barba y bigote. La reversión es total. Ana se convierte en hombre y se infiere que Manuel se transforma completamente en mujer y por eso nadie lo puede recordar. Como mujer, Manuel desaparece del mundo de Ana, quien termina sola y transformada en hombre: "La soledad se presentó espesa, porque me sentía trunca, alguien andaba por alguna parte con algo muy mío. La soledad se me hizo dura, igual que mi cutis, tan azotado por esa navajilla, y que ya exigía dos afeitadas diarias" (40-1).

Willy Muñoz hace un análisis exhaustivo del valor lingüístico y semántico de las palabras de Ana y de su efecto paródico: "Este relato . . . constituye una parodia de la voz masculina que codifica el cuerpo de la mujer" (104). Muñoz explica cómo las palabras de Ana, a través de la parodia que generan, establecen una codificación genérico-sexual que se plasma en oposiciones binarias que formulan una equivalencia de "hombre" con acción, y de "mujer" con pasividad (101). Ana, sin embargo, no es siempre pasiva, sino que se apropia de la voz masculina, y “desde la privilegiada perspectiva masculina, . . . denigra lingüísticamente el valor del cuerpo feminizado de Manuel” (102).

De hecho, Carmen Naranjo crea una situación inverosímil a partir de la cual propone un trastrueque no sólo de sexos sino también de géneros. Si se piensa en la visión tradicional de los géneros, lo que es típicamente femenino es no tener voz propia. En "Simbiosis" es la voz de Manuel la que se borra. Más aún, Manuel se pierde en la invisibilidad después de que se transforma en mujer. Ana, aunque sola, termina siendo dueña de su espacio y de su discurso. No constituye, sin embargo, esta metamorfosis de Ana, una reivindicación de la mujer, pues Ana simplemente se transforma en hombre, y en este cambio, asume la conducta estereotípica masculina.

"Simbiosis" plantea el carácter construido de los géneros. Esta idea sigue una escuela de pensamiento feminista que ya comienza a definirse más sólidamente en la década de los ochenta. Se podría identificar quizá como punto de partida el famoso postulado de Simone de Beauvoir, en el que, en los primeros años de los 50, señala que la mujer no nace sino que se hace. De Beauvoir, por supuesto, alude al carácter construido de la feminidad, y por lo tanto, de lo que se entiende por ser mujer. Pero "Simbiosis" sugiere mucho más que la noción de género como construcción cultural. Este cuento muestra en forma directa que el lenguaje es el agente y el vehículo de toda construcción mental o cultural. Para la transformación de Ana, por ejemplo, no son suficientes los cambios en su aspecto físico. Se requieren, con igual importancia, los cambios en sus estrategias discursivas.

Ana y Manuel, en sus respectivas transformaciones, nos obligan a pensar en el registro social del concepto de género y en los orígenes e implicaciones que tiene tal registro. Como bien explica Anne Cranny-Francis, al discutir la teoría feminista de Judith Butler, "gender is the discursive practice which subsequently constitutes bodies as "naturally sexed"" (28). Es decir, la construcción socio-cultural de los géneros hace que una codificación cultural se registre a nivel 
social como un fenómeno biológico-natural. Cranny-Francis explica que muchas de las codificaciones culturales del pensamiento occidental parten del dualismo mente-cuerpo, que, a su vez, genera muchas oposiciones binarias, siendo la más significativa la de hombre (que se asocia con mente) y mujer (que se asocia con cuerpo). A pesar de esta asociación, el cuerpo, cuando se teoriza o se piensa en abstracto; es un cuerpo masculino: "feminist theorists were concerned at the philosophical and practical implications of the fact that, whenever the body is abstractly thought of, it so often assumes masculine characteristics-despite the fact that the body is aligned metaphorically with the feminine" (23).

El texto de Naranjo revierte el alineamiento metafórico referido y propone que el hombre experimente las transformaciones corporales y biológicas que experimenta la mujer. En este sentido, "Simbiosis" parecería reafirmar lo que propone Judith Butler en su teoría de las diferencias de género. Como resume Cranny-Francis, "Butler concludes that by noting that since gender is a performative act (that is, not a reified concept but a practice) which gains credence through repetition, the possibilities of gender-transformation lie in disrupting such repetition" (32).

Carmen Naranjo, en "Simbiosis," irrumpe en esta repetición y la perturba al hacer que una mujer se apropie de la voz y el cuerpo masculinos. Ana, en su masculinización, es egoísta, insultante, abusiva y denigrante frente a Manuel, feminizado. Manuel, en su feminización, se vuelve dependiente, miedoso, y es, finalmente, silenciado. Es más, Ana ve a Manuel, con su cuerpo embarazado, como grotesco y monstruoso, y asume los estereotipos sociales con respecto a este cuerpo transformado. "Simbiosis", pues, propone la idea feminista del cuerpo como inscripción discursiva. Esta inscripción, en el texto de Naranjo, fluye libremente, sin tener que obedecer patrones establecidos.

Naranjo representa con claridad la ambivalencia con que la sociedad occidental percibe el cuerpo de la mujer embarazada. En forma paradójica, este cuerpo se sacraliza al mismo tiempo que se denigra. El carácter sagrado del cuerpo femenino en estado de embarazo explica y mantiene el alejamiento y rechazo masculinos: al ser sagrado ya no es humano, y, por consiguiente, el hombre no puede ni debe aspirar a ningún contacto con él. El contacto físico, más bien, desacralizaría el cuerpo femenino embarazado y, en este proceso, lo convertiría en agente de horror. En este sentido, el cuerpo de una mujer embarazada es percibido como el cuerpo de un monstruo. Braidotti lo explica de la siguiente manera: "the woman's body can change shape in pregnance and childbearing: it is therefore capable of defeating the notion of fixed bodily form, of visible, recognizable, clear, and distinct shapes as that which marks the contour of the body. She is morphologically dubious" (64).

Es evidente que los dos cuentos de Carmen Naranjo subvierten patrones establecidos. Pero estas "subversiones" no implican necesariamente una mejor situación para los personajes. Mercedes, para Vega, es un simple medio para lograr un fin; por otro lado, Vega no tiene conciencia de su subordinación, y Ondina, en su hedonismo, es totalmente indiferente a los sentimientos de los demás. Al mismo tiempo, Ana, en su cambio de postura y de conducta, sufre una metamorfosis que le da la máscara de una identidad masculina. Finalmente, parece decir Naranjo, hombres y mujeres se ocultan tras la máscara del estereotipo, y desde la comodidad que confiere la expectativa social, continúan favoreciendo el status quo normativo.

"Ondina" y "Simbiosis", de hecho, constituyen una resistencia y una confrontación a los patrones establecidos que afectan especialmente a la mujer. ¿Podríamos, entonces, decir que estos cuentos presentan la posibilidad de una sociedad más justa y equitativa? En parte 
sí, pero no creo que la respuesta sea del todo afirmativa. En "Simbiosis", la reversión es tal que parece una representación directa de la ley del talión: el hombre tendrá que pagarle a la mujer siendo sometido y denigrado de la misma manera en que ella se somete y es denigrada. ¿Significa esto una reivindicación de la mujer o del discurso femenino? ¿Sugiere que Ana, como representante de la mujer, asume aquí un papel no sumiso, activo, en control? Y las respuestas, para ambas preguntas, son, "en parte". De hecho, el cuento sugiere cambios que afectan a los personajes. El modo en que se ven afectados quizá sea el paso inicial para que se desarrolle cierta conciencia de las acciones que los personajes masculinos y los femeninos realizan con el lenguaje.

En "Ondina", como señalé antes, Vega se "enamora" sobre la base de lo que él proyecta en Ondina, y no de las características personales de ella. Y cuando la proyecta, la imagina bella. ¿Quiebra Vega, entonces, la expectativa masculina del estereotipo de la belleza femenina? ¿Hasta qué punto se puede aceptar que esté enamorado de Ondina? ¿Acaso no la usa para satisfacer sus fantasías sexuales? ¿Reivindica Ondina el lugar de la mujer con respecto al mito de la belleza femenina? ¿En qué consiste, finalmente, el carácter femenino de Ondina? Algunas de estas preguntas permanecen sin respuesta, pero el logro de Naranjo es hacer que los lectores se las formulen y que revisen asuntos que quizá antes de los ochenta no habían sido cuestionados.

A pesar de los cuestionamientos que propone la lectura de ambos cuentos, es innegable que "Ondina" y "Simbiosis del encuentro" constituyen un acto de rebeldía frente a los patrones normativos de la sociedad aún machista. Carmen Naranjo, a comienzos de los ochenta, se hace precursora del continuo diálogo que se suscitará luego entre las teóricas del feminismo hispanoamericano.

"Ondina" y "Simbiosis del encuentro", además, invitan a que consideremos las limitaciones de nuestro conocimiento cuando creemos que sabemos mucho o que lo sabemos todo. Vega y Ana creen conocer bien su situación y creen saber lo que quieren. Naranjo nos hace ver que el conocimiento no se puede hacer independiente del discurso. Conocer implica un modo de operar -con lenguaje- en el mundo. Ana y Vega operan sobre la base de su imaginación, de suposiciones, y patrones socialmente preestablecidos. Sus estrategias discursivas hacen que se entrampen aún más en esas suposiciones y en esos patrones. Más aún, sus estrategias discursivas les impiden tener la capacidad introspectiva para darse cuenta de esto. De este modo, toda posibilidad de que desarrollen esta capacidad está saboteada por su propio discurso. Estos dos cuentos de Naranjo, además, confirman que las oposiciones binarias, así como son construidas, pueden desconstruirse. Para una posterior reconstrucción positiva, sin embargo, es necesario que haya conciencia, sobre todo, conciencia del lenguaje que genera la primera construcción. En este sentido, la responsabilidad recae sobre todos los miembros de la sociedad, parece sugerir la autora costarricense.

Y, efectivamente, como le expresa a Chalene Helmuth en su entrevista, Naranjo muestra que cuerpo es una palabra clave, y por lo tanto un concepto clave: "es algo que define [a la mujer] frente a todos, pero que no la define a una misma" (49). "Ondina" y "Simbiosis del encuentro", con parodia e ironía, confirman, de manera indirecta, esta idea. Sin embargo, Carmen Naranjo, en estos dos cuentos, propone que no sea el cuerpo lo que define a la mujer, y lo hace desconstruyendo la idea del cuerpo y de la belleza femeninos. En ambos cuentos la autora desmitifica el cuerpo de la mujer. Y quizá sólo después de esta desmitificación se pueda plantear la reformulación de la idea del cuerpo femenino, y, por consiguiente, de la belleza femenina. 


\section{Bibliografía}

Bartky, Sandra Lee. "Foucault, Femininity, and the Modernization of Patriarchal Power". En: Katie et al (eds.),129-154.

Borloz Soto, Virginia. “Presentación del libro 'Más allá del Parismina' de la escritora Carmen Naranjo”. Citado en: www.Ctcr.ac.cr/revistacomunicacion/1_2001finalpresentacion_ del_libro.htm.

Braidotti, Rosi. "Mothers, Monsters, and Machines”. En: Katie et al (eds.), 59-79.

Conboy, Katie et al (eds.). 1997. Writing on the Body. Female Embodiment and Feminist Theory. New York: Columbia University Press.

Cranny-Francis, Anne. 1995. The Body in the Text. Victoria: Melbourne University Press.

Helmuth, Chalene. 1996. "Entrevista a Carmen Naranjo". Hispamérica. Revista de Literatura. 74: 47-56.

Morton, Lisa. 1995. "Crush and Sweetie: the Female Grotesque in Two Contemporary Australasian Films". Deep South. 1 (3). http://www.otago.ac.nz/DeepSouth/vol1n3/ morton_issue3.html.

Muñoz, Willy. 2000. “El lenguaje y la devaluación del cuerpo preñado en 'Simbiosis del encuentro’ de Carmen Naranjo”. Letras Femeninas. XXVI (1-2): 99-110.

Naranjo, Carmen. 1985. “Ondina”. Ondina. San José: EDUCA, 2 ed.: 9-18.

1985. “Simbiosis del encuentro.” Ondina. San José: EDUCA: 35-42.

Russo, Mary. 1997. "Female Grotesques: Carnival and Theory.” En: Katie et al (eds.): 318336. 